\title{
Development of a portable active long-path differential optical absorption spectroscopy system for volcanic gas measurements
}

\author{
F. Vita ${ }^{1}$, C. Kern ${ }^{2}$, and S. Inguaggiato ${ }^{1}$ \\ ${ }^{1}$ Istituto Nazionale di Geofisica e Vulcanologia - Sezione di Palermo - Via Ugo La Malfa, 153, \\ 90146 Palermo, Italy \\ ${ }^{2}$ U.S. Geological Survey, Cascades Volcano Observatory, 1300 SE Cardinal Ct S100, Vancouver, \\ Washington 98683, USA \\ Correspondence to: F. Vita (fabio.vita@ingv.it)
}

Received: 16 April 2014 - Revised: 5 November 2014 - Accepted: 8 November 2014 - Published: 19 December 2014

\begin{abstract}
Active long-path differential optical absorption spectroscopy (LP-DOAS) has been an effective tool for measuring atmospheric trace gases for several decades. However, instruments were large, heavy and powerinefficient, making their application to remote environments extremely challenging. Recent developments in fibre-coupling telescope technology and the availability of ultraviolet light emitting diodes (UV-LEDS) have now allowed us to design and construct a lightweight, portable, low-power LP-DOAS instrument for use at remote locations and specifically for measuring degassing from active volcanic systems. The LP-DOAS was used to measure sulfur dioxide $\left(\mathrm{SO}_{2}\right)$ emissions from La Fossa crater, Vulcano, Italy, where column densities of up to $1.2 \times 10^{18}$ molec cm$^{-2}(\sim 500 \mathrm{ppmm})$ were detected along open paths of up to $400 \mathrm{~m}$ in total length. The instrument's $\mathrm{SO}_{2}$ detection limit was determined to be $2 \times 10^{16}$ molec $\mathrm{cm}^{-2}$ ( $\sim 8 \mathrm{ppmm}$ ), thereby making quantitative detection of even trace amounts of $\mathrm{SO}_{2}$ possible. The instrument is capable of measuring other volcanic volatile species as well. Though the spectral evaluation of the recorded data showed that chlorine monoxide $(\mathrm{ClO})$ and carbon disulfide $\left(\mathrm{CS}_{2}\right)$ were both below the instrument's detection limits during the experiment, the upper limits for the $\mathrm{X} / \mathrm{SO}_{2}$ ratio $\left(\mathrm{X}=\mathrm{ClO}, \mathrm{CS}_{2}\right)$ could be derived, and yielded $2 \times 10^{-3}$ and 0.1 , respectively. The robust design and versatility of the instrument make it a promising tool for monitoring of volcanic degassing and understanding processes in a range of volcanic systems.
\end{abstract}

\section{Introduction}

The emission of volatile species from volcanic magmas is linked to geochemical processes occurring at depth. Volatiles are exsolved as a result of recharge, decompression, crystallisation or mixing of magmas. The composition and flux of gases being emitted from a volcanic vent can provide insights into geophysical and geochemical parameters such as magma supply, pressure, temperature and degassing depth parameters that can used by volcanologists to forecast eruptions.

The major volatile species emitted from volcanic vents are water vapour $\left(\mathrm{H}_{2} \mathrm{O}\right)$, carbon dioxide $\left(\mathrm{CO}_{2}\right)$, sulfur dioxide $\left(\mathrm{SO}_{2}\right)$, hydrogen sulfide $\left(\mathrm{H}_{2} \mathrm{~S}\right)$ and hydrogen halides ( $\mathrm{HX}$ with $\mathrm{X}=\mathrm{Fl}, \mathrm{Cl}, \mathrm{Br}, \mathrm{I})$. Of these, $\mathrm{CO}_{2}$ has the lowest solubility in most magma types, and is typically emitted first as a magmatic system is recharged (Werner et al., 2013; Burton et al., 2013). Therefore, developing methods for accurately monitoring $\mathrm{CO}_{2}$ emissions from volcanoes has been a major focus of the volcanology community in recent years.

Unfortunately, volcanic $\mathrm{CO}_{2}$ emission rates are considerably more difficult to measure than those of some of the other species, the main reason being the significant background concentration of $\mathrm{CO}_{2}$ in the Earth's atmosphere. Unless measurements are made very close to the vent where high magmatic/atmospheric gas ratios can be sampled, the enhancement of $\mathrm{CO}_{2}$ in a volcanic plume is oftentimes only a few parts per million (ppm) over the background of 
approximately $400 \mathrm{ppm}$. Passive remote sensing instruments that use scattered solar radiation as a light source and therefore make an integrated measurement over the entire atmospheric column attempt to detect an even smaller enhancement. The relative increase in the total $\mathrm{CO}_{2}$ column is of the order of only $10^{-3}$ for large emitters and can be significantly less at volcanoes with moderate to small emission rates. For this reason, $\mathrm{CO}_{2}$ emissions from volcanoes have not yet been detected from satellite platforms, and direct measurements of $\mathrm{CO}_{2}$ emission rates from volcanic vents can only be made by laborious and costly aircraft traverse techniques (Gerlach et al., 1997).

On the other hand, $\mathrm{SO}_{2}$ has a negligible atmospheric background concentration and is much more accessible to remote sensing observations, with routine measurements made both from ground-based and satellite-based instrumentation (Galle et al., 2010; Oppenheimer et al., 2011; Carn et al., 2013). In fact, arguably the most robust method currently available for measuring volcanic $\mathrm{CO}_{2}$ emission rates is by determining the molecular ratio of $\mathrm{CO}_{2}$ to $\mathrm{SO}_{2}$ in a volcanic plume and multiplying this by the $\mathrm{SO}_{2}$ molecular emission rate obtained from remote sensing instrumentation (Gerlach et al., 1998; Burton et al., 2013; Pering et al., 2014). $\mathrm{CO}_{2} / \mathrm{SO}_{2}$ molecular ratios can either be determined by collecting gas in Giggenbach bottles (Giggenbach and Goguel, 1989) for analysis in the laboratory or using in situ chemical and optical sensors in a multicomponent gas analyzer system (Multi-GAS, Aiuppa et al., 2005; Shinohara, 2005). While the sampling of fumaroles with Giggenbach bottles is limited in its applicability for continuous monitoring, these relatively novel Multi-GAS instruments now allow real-time measurements of volcanic gas compositions suitable for eruption forecasting (Aiuppa et al., 2007).

Despite their relative versatility, the Multi-GAS instruments also have some drawbacks, and determining the gas speciation representative of the bulk plume at a volcanic vent remains challenging. For one, the instruments typically rely on an optical $\mathrm{CO}_{2}$ sensor and multiple electrochemical sensors for other gas species (Aiuppa et al., 2005). The different sensors tend to have significantly different response times, with the optical sensor being quicker to respond to a change in composition than the electrochemical sensors. This can lead to errors and uncertainties in the derived gas ratios if not properly taken into account (Roberts et al., 2014). Also, the electrochemical sensors have cross-sensitivities to other gases - oftentimes gases found in great abundance in volcanic plumes (Roberts et al., 2012). A typical electrochemical $\mathrm{H}_{2} \mathrm{~S}$ sensor, for example, can have a cross-sensitivity to $\mathrm{SO}_{2}$ of up to $20 \%$ (Roberts et al., 2014). Finally, while in situ sampling lends itself to deriving the gas composition at a specific location, problems arise if the volatile speciation is heterogeneous in space in the area around the volcanic vent. Such heterogeneities are quite common, and can be caused by a complex plumbing system and interaction of volatiles with a hydrothermal system, or result from gas and fluid temperature variations in the proximity of the vent. In such cases, the gas composition measured by an in situ measurement may not be representative of the bulk plume.

In light of these challenges, improved methods for measuring plume compositions at volcanic vents are still being sought. One very sophisticated method is to use Fourier transform infrared spectroscopy (FTIR) to measure the absorption or emission of infrared (IR) radiation by volcanic gases (Oppenheimer et al., 1998; Stremme et al., 2012). FTIR is sensitive to a large number of species, including both $\mathrm{CO}_{2}$ and $\mathrm{SO}_{2}$, and can therefore be used in combination with $\mathrm{SO}_{2}$ emission rate measurements to derive $\mathrm{CO}_{2}$ emission rates (Burton et al., 2000). When used in an open-path configuration with the light path penetrating the bulk plume, representative gas compositions can be obtained. However, FTIR instruments are very costly and limited in their portability, as they rely on a moving interferometer to record spectral information. Also, deployment can be challenging in the absence of accessible hot lava, as they then require either a bulky thermal IR emitter requiring tens of watts of power to be deployed on the opposite side of the vent, or must be located such that the plume is between the instrument and the Sun, which is then used as an IR source.

Near-infrared (NIR, $800 \mathrm{~nm}<\lambda<2500 \mathrm{~nm}$ ) tuneable diode laser absorption spectroscopy (TDLAS) instruments represent a somewhat simpler alternative (Schiff et al., 1994; Carapezza et al., 2011; Pedone et al., 2014). Although typically only sensitive to a single gas species according to which the laser wavelength is chosen, today's NIR-TDLAS units are small and portable, typically weighing $\sim 2.5 \mathrm{~kg}$, and can run for extended periods of time on battery power. When set up in an open-path configuration, these instruments only require that a retroreflector be deployed on the opposite side of the desired optical path, as both the light source and the detector are usually located in the same unit. Reflectors are considerably simpler to deploy than active light sources, as they do not require power, do not need to be carefully adjusted and can withstand harsh environmental conditions more easily. NIR-TDLAS instruments measuring $\mathrm{CO}_{2}, \mathrm{H}_{2} \mathrm{~S}$, $\mathrm{HF}$ or $\mathrm{CH}_{4}$ along open paths are commercially available for purchase.

Measuring $\mathrm{SO}_{2}$ in the infrared absorption is also possible, but due to the lack of near-infrared (NIR) absorption bands, measurements are made in the thermal infrared regions $(3.5 \mu \mathrm{m}<\lambda<20 \mu \mathrm{m})$. Though the technology of thermal infrared lasers is constantly evolving (Tittel et al., 2012), they remain considerably more complex than NIR diode lasers, and generally require significantly more power. Depending on which thermal IR band is chosen, additional complications can arise from interference by pressure-broadened absorption lines of other atmospheric compounds (mainly $\mathrm{CO}_{2}$ and $\mathrm{H}_{2} \mathrm{O}$ ). Therefore, IR laser absorption measurements of $\mathrm{SO}_{2}$ are usually performed in cells at reduced barometric pressures (Richter et al., 2002; Rawlins et al., 2005), and no IR laser absorption measurements of $\mathrm{SO}_{2}$ along open 
atmospheric paths are known to date. In the absence of an $\mathrm{SO}_{2}$ measurement, emission rates of gases detected using NIR-TDLAS cannot easily be determined using the ratio method described earlier.

For this reason, implementation of a portable, active openpath measurement of $\mathrm{SO}_{2}$ is highly desirable. In this study, we describe how a miniature active long-path differential optical absorption spectroscopy (LP-DOAS) instrument was designed to measure $\mathrm{SO}_{2}$ and potentially also other trace gases with a high degree of accuracy and precision along well-defined open paths around volcanic vents. Emphasis was placed on ensuring portability of the instrument on foot to remote locations, a sufficient degree of environmental hardening, low power consumption that can easily be supplied by battery, and simple set-up and removal at the target site. After the instrument was constructed, tests were performed at the island of Vulcano (Aeolian arc, Italy) in February 2010, the results of which are described below.

\section{Design of a portable LP-DOAS instrument}

The first measurements of atmospheric trace gases by LPDOAS were performed in the late 1970s (Platt et al., 1979). The technique has since become widely used in the atmospheric sciences community, particularly because the contact-free nature of the measurement allows the detection of highly reactive radical species (Platt and Stutz, 2008). More recently, active differential absorption measurements have also been applied to volcanic gases (O'Dwyer, 2003; Kern et al., 2008), but deployment of active LP-DOAS systems has been severely limited by the size (a typically longer than $1 \mathrm{~m}$ focal length telescope) and weight (typically tens to hundreds of $\mathrm{kg}$ ) of such systems and by the power consumption of the ultra-violet light sources required (typically tens to hundreds of watts).

Two recent technological advances have now made it possible to design a lightweight portable LP-DOAS instrument. For one, the size and weight of the telescope unit can be dramatically reduced by replacing the conventional Newtonian set-up with a fibre-coupling coaxial design. In this set-up, first introduced by Merten et al. (2011), the light source is coupled into the telescope using a fibre bundle, one end of which is placed in the focal plane of the spherical primary mirror. Light from the desired light source is coupled into several of the fibres in the bundle, reflected on the primary mirror, and transmitted in a nearly parallel beam into the atmosphere to an array of retroreflectors located tens or hundreds of metres away. These reflect the light back to the primary mirror of the telescope, where, partly due to spherical aberration of the mirror, some of it enters the receiving fibres that couple it into a moderate resolution ultraviolet (UV) spectrometer for analysis. The use of this fibre-coupling design eliminates the need for any secondary mirrors and al- lows separation of the light source from the telescope, thus making a lighter, portable telescope design possible.

In our design, the fibre bundle consists of seven $100 \mu \mathrm{m}$ diameter fused silica fibres, six of which are arranged in a circular pattern around a central seventh fibre. As suggested by Merten et al. (2011), we use the six outer fibres of the bundle for transmission and the central fibre to receive radiation that has passed through the optical system. However, we have modified the original design by additionally splitting the transmission fibres into three groups of two (Fig. 1). This allows the coupling of three different light sources into the optical path, a feature that is unique to our system and allows a high degree of flexibility with regard to measurement wavelength (see below).

In this coaxial set-up, the telescope primary mirror acts both as a sending and receiving unit. A three-dimensional fibre positioner is used to mount the end of the fibre bundle in the focal plane of the mirror (Fig. 1), which is protected from environmental conditions by an $\mathrm{MgF}_{2}$ coating. Compared to previously described LP-DOAS systems, we use a significantly smaller primary mirror diameter $d$ of only $150 \mathrm{~mm}$ with a focal length $f$ of $400 \mathrm{~mm}$ to reduce the overall instrument size and weight. In the paraxial approximation, and considering the fibre bundle diameter of about $300 \mu \mathrm{m}$, this set-up leads to a beam spread angle $\alpha$ of approximately 0.04 degrees. The diameter $D$ of the retroreflector array required to reflect the entire emitted radiation back to the telescope is then given by

$D=d+2 L \tan \left(\frac{\alpha}{2}\right) \approx d+L \tan \alpha$.

Here, $L$ is the distance between the telescope and reflector array, which is also exactly half of the optical path length. In our set-up, an array diameter of $19 \mathrm{~cm}$ is needed at a distance of $50 \mathrm{~m}$. For a path length of $200 \mathrm{~m}$, an array diameter of $29 \mathrm{~cm}$ is required to reflect all transmitted radiation. A larger telescope would reduce beam spread, but the compact design chosen here makes the instrument portable and allows measurements to be made in otherwise inaccessible remote locations. Path lengths of up to a few hundred metres are sufficient for making measurements at most volcanic vents. For the test measurements, we used an array of ten $52 \mathrm{~mm}$ diameter fused silica corner cubes densely packed in a triangular frame mounted on a tripod. This array had a total diameter of approximately $40 \mathrm{~cm}$, thus allowing one-way paths of up to about $350 \mathrm{~m}$ without significant loss of radiative energy. We successfully made measurements along paths of up to $200 \mathrm{~m}$ with the set-up (see Sect. 3).

For one-way paths longer than $350 \mathrm{~m}$, one might expect a significant drop in the measurement signal-to-noise ratio (SNR). Because the fraction of reflected light is proportional to $D^{-2}$ and therefore proportional to $L^{-2}$ for long light paths (Eq. 1), photon statistics yield an SNR of the measured spectrum that is proportional to the square root of the intensity, or $L^{-1}$. However, since the column density is proportional to 
(a)
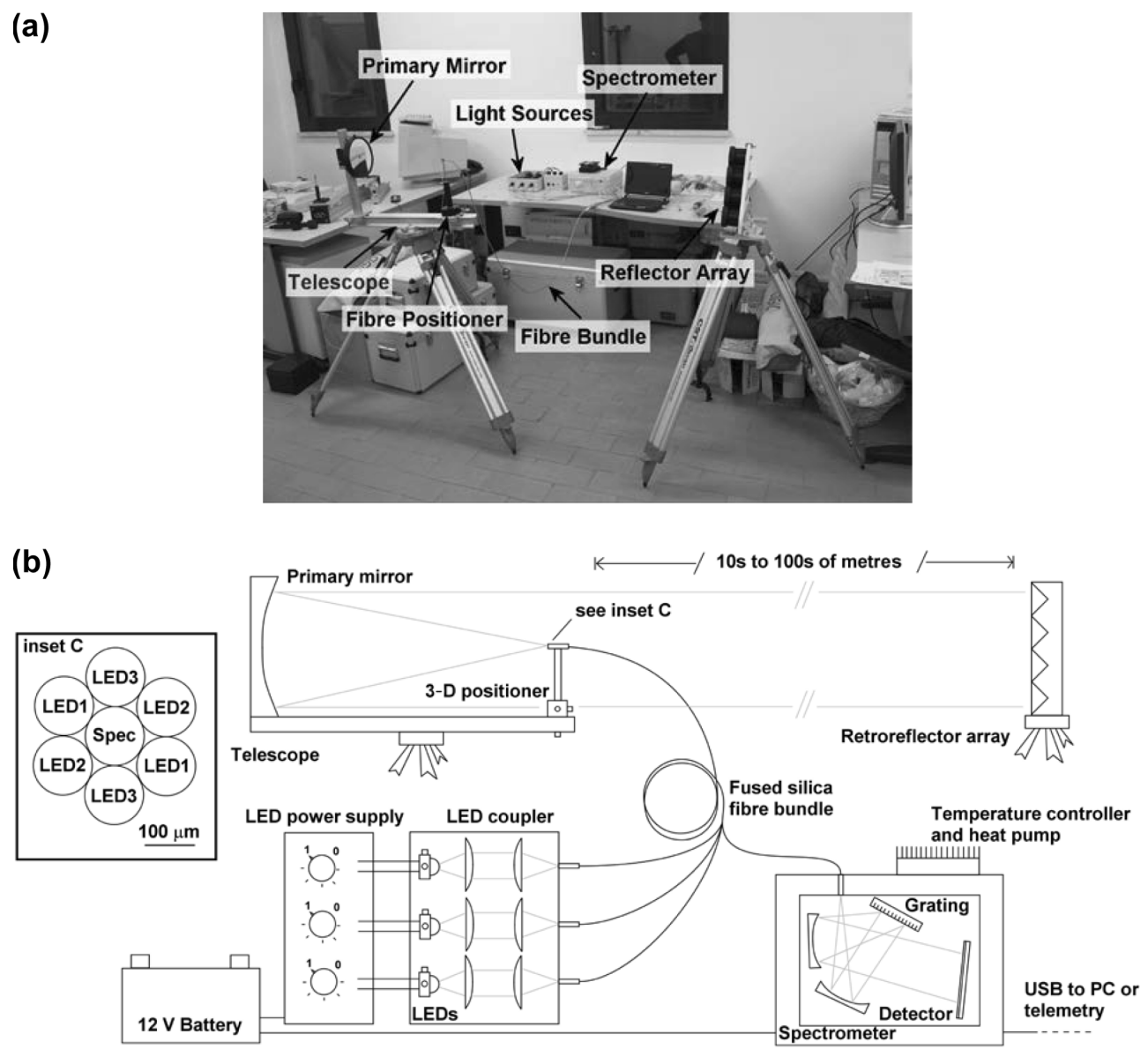

Figure 1. Photograph (a) and schematic (b) of the portable active long-path DOAS instrument. Light from three UV LEDs is coupled to a fibre bundle, collimated to a parallel beam and sent to an array of reflectors. Upon returning, it is coupled to a moderate-resolution UV spectrometer for analysis of absorption features.

the light path length (if the plume fills the optical path), the measured optical depth will be proportional to $L$, thus yielding a measurement SNR that is, in first order, independent of the light path length. However, if opaque volcanic plumes are measured, scattering of light out of the optical path by aerosols and water droplets will further decrease the SNR, particularly for longer light paths (see Sect. 4.2).

In addition to allowing for a decoupling of the light source from the telescope, the fibre design allows for fine adjustments of the beam direction without the need to adjust the pointing direction of the telescope (Merten et al., 2011). After aiming the telescope in the vicinity of the reflectors, slight adjustments to the fibre position can be used to finetune the pointing direction of the instrument. This technique, however, requires that the $f / \#$ of the telescope be smaller than that of the spectrometer. In other words, the area from which light is collected by the spectrometer must be smaller than the primary mirror. If this is not the case, light that has not passed along the optical path can enter the system from adjacent to the telescope primary mirror when the fibre bundle is moved out of the focal point. We avoid this problem by using an $f / 2.7$ telescope and an $f / 4$ spectrometer. The $f / 4$ spectrometer collects light from a circular $10 \mathrm{~cm}$ diameter subsection of the primary mirror, so the fibre bundle can be moved up to about $2.5 \mathrm{~cm}$ to each side of the focal point without collecting light from beside the mirror. This allows adjustment of the telescope pointing direction by \pm 3.6 degrees in the left/right and up/down directions without moving the telescope itself.

The second technological advance which allowed us to design a portable LP-DOAS instrument is the availability of an efficient UV light source. Besides the weight of the instrument itself, the application of LP-DOAS systems in remote locations has also been severely limited by the high power consumption of conventional UV light sources. Typical light sources such as xenon arc and deuterium lamps only emit a fraction of their consumed energy as optical output - by far the majority of the energy is lost to wavelengths that are not relevant for the measurement, especially in the thermal IR. The advent of UV-LEDs and their applicability to LPDOAS instruments has now revolutionised the achievable power efficiency of such systems (Kern et al., 2006; Sihler et 
al., 2009). By utilising three UV LEDs with maximum emission wavelengths at 285,310 and $315 \mathrm{~nm}$ instead of a gas discharge lamp, the power consumption of the light source was reduced from what was typically between 50 and $500 \mathrm{~W}$ to less than $1 \mathrm{~W}$ without significantly affecting the optical output power at the required wavelengths. We used Sensor Electronic Technology UVTOP285, UVTOP310 and UVTOP315 flat window LEDs with maximum emission wavelengths of 285, 310 and $315 \mathrm{~nm}$, respectively. Each consuming approximately $180 \mathrm{~mW}$ of electrical power, these LEDs are rated as emitting between 600 and $800 \mu \mathrm{W}$ of optical power at wavelengths within approximately $\pm 15 \mathrm{~nm}(12 \mathrm{~nm}$ FWHM) around their peak emission (Sensor Electronic Technology, 2014).

As shown in Fig. 2, the UV LED wavelengths were chosen to overlap with the differential absorption features of $\mathrm{SO}_{2}$, chlorine monoxide $(\mathrm{ClO})$ and carbon disulfide $\left(\mathrm{CS}_{2}\right)$ (Bogumil et al., 2003; Vandaele et al., 2009). However, other LEDs can be chosen to target other species (e.g. bromine monoxide $(\mathrm{BrO})$ at $\sim 340 \mathrm{~nm}$, chlorine dioxide $(\mathrm{OClO})$ at $\sim 350 \mathrm{~nm}$ (Kern et al., 2008) or nitrogen dioxide $\left(\mathrm{NO}_{2}\right)$ at $\sim 350-450 \mathrm{~nm}$, Kern et al., 2006; Chan et al., 2012), or three LEDs of the same wavelength can be coupled to the system to enhance the SNR of the measurement in one specific wavelength region. The UV LEDs are each mounted on a 2-D positioner and coupled to the fibre bundle using two fused-silica plano-convex lenses (Fig. 1). The lens positioning along the optical axis is individually adjusted so as to provide maximum coupling efficiency for a given LED wavelength, thus avoiding chromatic aberration.

After the radiation has passed along the open optical path, the spectrum is analysed using an Ocean Optics QE65000 spectrometer with a cooled, back-illuminated CCD detector. The installed grating provided a wavelength range of 260 to $340 \mathrm{~nm}$ at a resolution of $0.5 \mathrm{~nm}$. The spectrometer was placed in an insulated enclosure and the temperature of the optical bench was stabilised using a pulse-widthmodulated thermoelectric cooling/heating unit to avoid fluctuations in calibration or other optical properties of the system. Excluding the notebook computer that was used for data collection in these test measurements, the power consumption of the entire system was below $25 \mathrm{~W}$ during continuous operation. This represents a considerable reduction in power use when compared to any previously reported LP-DOAS set-up, and allowed us to make battery-operated measurements.

The majority of the consumed power is actually used for temperature stabilisation of the spectrometer optical bench. The achieved temperature stability of better than $\pm 0.1^{\circ} \mathrm{C}$ is required when measuring weak absorption features of trace gases in the optical path of smaller than $\sim 0.01$ optical depth (see next section). If only gas species such as $\mathrm{SO}_{2}$ with relatively strong absorption bands are targeted, this stabilisation is not required, and the power consumption of the system can be reduced to as low as $5 \mathrm{~W}$ (depending on the CCD chip
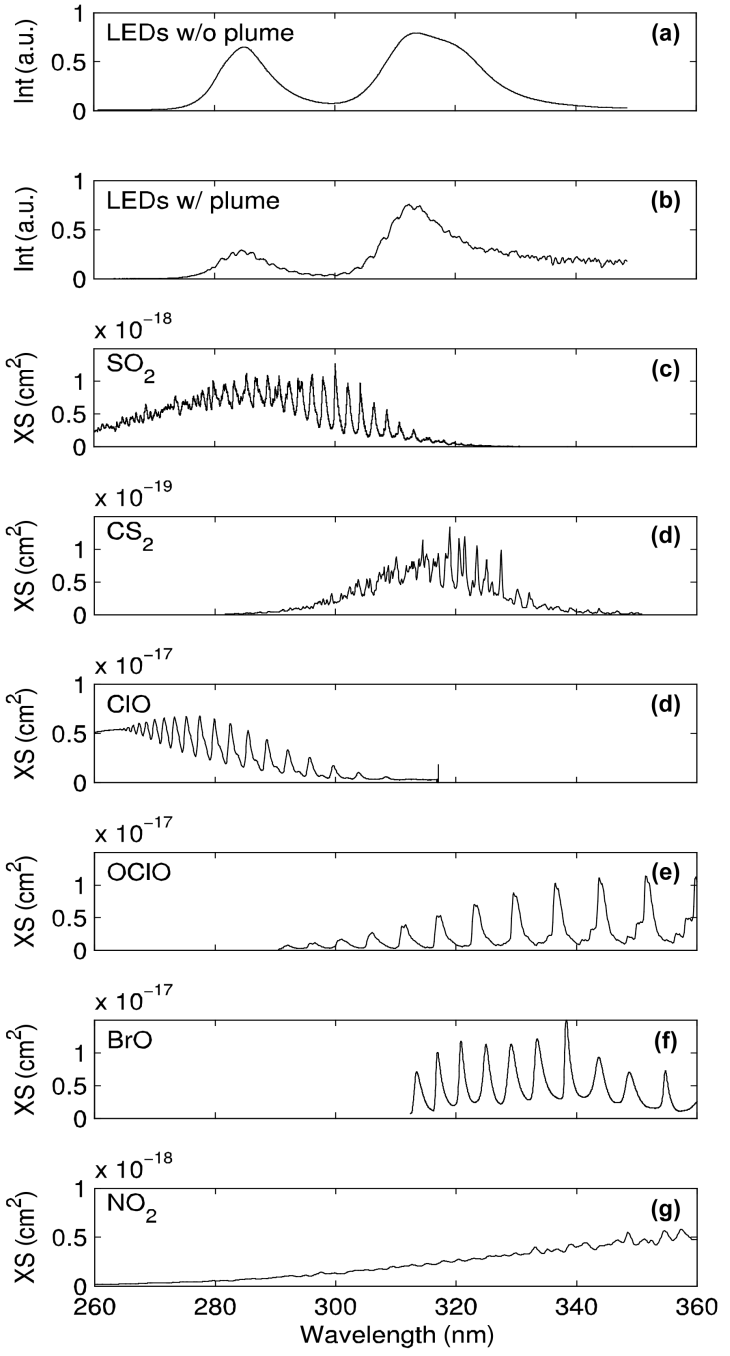

Figure 2. (a) Relative intensity of the three UV LEDs recorded when no plume was in the instrument's path. (b) Light intensity recorded when a plume drifted into the open path of the instrument. (c-f) Absorption cross sections (Wahner et al., 1988; Bogumil et al., 2003; Vandaele et al., 2009) of various trace gases that can be measured with the portable LP-DOAS system. Note that the LED emission spectrum overlaps the cross sections of $\mathrm{SO}_{2}, \mathrm{CS}_{2}$ and $\mathrm{ClO}$. The LEDs selected for these measurements were chosen specifically to provide sensitivity to these species.

temperature). During our test measurements described in the next section, we used a laptop computer for data acquisition. This added an additional $\sim 15 \mathrm{~W}$ to the total power consumption, and we chose to use a $45 \mathrm{Ah}, 12 \mathrm{~V}$ lead acid battery to run the measurements for the entire day. However, a set-up for making continuous measurements could either use a lowpower integrated PC or make use of a USB device server $(\sim 2 \mathrm{~W})$ instead of the laptop, and include a radio telemetry link $(\sim 5 \mathrm{~W})$ to the observatory where the spectral acquisition and processing would occur. Without temperature stabilisation (e.g. if only measuring $\mathrm{SO}_{2}$ ), the system could be run 
continuously in this set-up with a total power consumption of approximately $12 \mathrm{~W}$. Use of a solar power system for supplying the instrument power is therefore possible.

\section{Configuration of measurements at Vulcano}

On 25 February 2010, the portable LP-DOAS was tested at the island of Vulcano (Aeolian arc, Italy). Measurements were performed using two different light paths. During the first measurement period from approximately 12:00 to 12:45 local time, the array of retroreflectors was positioned behind a low-temperature fumarole about $100 \mathrm{~m}$ from the telescope (see Fig. 3a). During this time, the gases being emitted by this fumarole were measured. Little or no disturbance from other fumaroles is expected in this data set, as favourable winds were blowing the gases from other fumaroles in the area away from the light path. Depending on the wind, the light path length through the fumarolic gases was between 0 and $15 \mathrm{~m}$ one way, so a total light path of between 0 and $30 \mathrm{~m}$ resulted.

During the second measurement period, the reflectors were moved to a position farther down in the crater (approximately $200 \mathrm{~m}$ from the telescope) to enable the measurement of gases being emitted from the higher-temperature fumaroles located on the edge of the crater floor (Fig. 3b). The light path length inside the fumarolic gases varied considerably due to variations in wind direction as well as variations in the degassing strength of the fumaroles themselves.

\section{Evaluation of spectral data and measurement results}

\subsection{Spectral retrieval of $\mathrm{SO}_{2}$}

Due to its importance as a tracer for other volcanic gases (see Sect. 1), $\mathrm{SO}_{2}$ is the primary target species for the LPDOAS instrument. $\mathrm{SO}_{2}$ has several distinct absorption features in the spectral region between 260 and $320 \mathrm{~nm}$, the strongest of which lie around $300 \mathrm{~nm}$ (Vandaele et al., 2009, Fig. 2). However, we chose to measure the differential absorption of $\mathrm{SO}_{2}$ between 280 and $290 \mathrm{~nm}$, because the relatively high column densities generally encountered in the plumes of active volcanoes make absolute sensitivity a secondary concern. More importantly, the ability to measure at shorter wavelengths eliminates any interference from scattered solar radiation entering the spectrometer, as the ozone layer effectively absorbs all incident solar radiation at wavelengths shorter than $300 \mathrm{~nm}$ (Hartley absorption bands). A UVTOP LED with a $285 \mathrm{~nm}$ peak transmittance wavelength was selected for this purpose.

The $\mathrm{SO}_{2}$ column density was derived from each measured spectrum using a DOAS retrieval. First, each spectrum was corrected for the electronic offset of the spectrometer. This offset is added to each measured spectrum by the spectrometer electronics prior to digitisation in order to avoid nega-
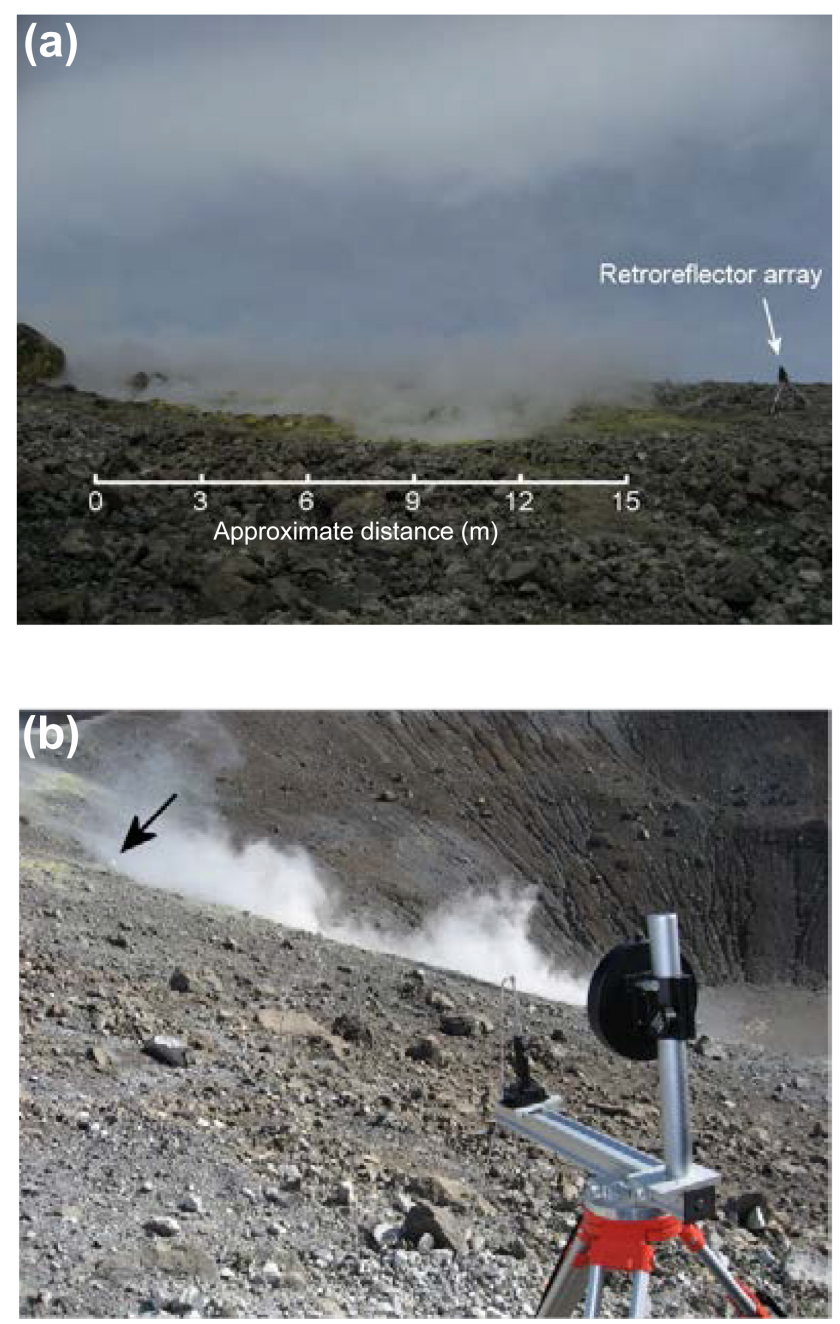

Figure 3. (a) Location of the retroreflector array during the first experiment on the island of Vulcano on 25 February 2010. The telescope was situated approximately $100 \mathrm{~m}$ off to the left of this photograph, but only the last $15 \mathrm{~m}$ of the one-way optical path were filled intermittently with gas from the low-temperature fumaroles shown here, depending on the wind direction. (b) Configuration of the second experiment. Here, the retroreflector array (indicated by an arrow) was located approximately $200 \mathrm{~m}$ from the telescope and farther down in the crater of the volcano. Gases originating from the higher-temperature fumaroles at the base of the crater would intermittently blow into the optical path.

tive intensity values. It is best measured by co-adding a large number of exposures at very short exposure time and with no incident light. Since the electronic offset is added to each exposure, the co-added spectrum is then divided by the number of exposures, multiplied by the number of exposures in the measurement spectrum, and then subtracted from it.

In the next step, each measurement spectrum is corrected for the detector dark current. This contribution stems from thermal excitation of electrons in the CCD detector, and is proportional to the exposure time. It is therefore best 
characterised by taking a long exposure of the CCD with no incident radiation. After subtracting the offset, the dark current spectrum is divided by the exposure time, multiplied by the exposure time of the measurement spectrum, and then subtracted from it. Note that both the offset and dark current are typically dependent on the temperature of the spectrometer. However, since the spectrometer and the CCD detector were both kept at a stable temperature during our measurements, characterisation of the offset and dark current could be performed before and after the measurements were made.

In order to evaluate only the differential absorption features in a measured spectrum, the next step is to derive the differential optical density $\tau^{\prime} . \tau^{\prime}$ is defined as the negative logarithm of the ratio of measured intensity $I$ to transmitted intensity $I_{0}$ which, according to the Beer-Lambert-Bouguer law of absorption, is proportional to the column density $S$ of the absorber in the light path.

$\tau^{\prime}=-\ln \left(\frac{I}{I_{0}}\right)=\sigma \cdot S$

Here, $\sigma$ is the absorption cross section of the absorbing gas. The initial intensity $I_{0}$ is the spectrum of the light sources before the radiation has passed through the atmosphere. Since $I_{0}$ can depend on the temperature of the LEDs (Kern et al., 2006; Sihler et al., 2009), it is best measured in close temporal proximity to the measurement spectra. In LPDOAS instruments, characterisation of the light sources can be performed using a "shortcut" system which redirects light emitted from the light sources directly into the spectrometer without passing along the optical path. Since we use a fibre assembly to couple radiation into and out of the telescope, a shortcut system can be implemented by simply placing a reflective diffusor plate in front of the fibre bundle in the focal point of the mirror (Merten et al., 2011). Radiation emitted from the fibre ring is scattered on this plate and, in part, enters the central collection fibre for analysis. In between measurements, we manually inserted a sand-blasted aluminium plate a few $\mathrm{cm}$ from the fibre bundle and measured $I_{0}$. However, owing to the variable wind directions encountered within the La Fossa crater, we also intermittently obtained measurement spectra with no volcanic gas in the light path of the instrument. These were later found to be the best measure of $I_{0}$, because exactly the same optical path through the instrumentation is used as during the measurements, only in the absence of volcanic gas. In our evaluations, we co-added 60 such spectra and used these as an LED reference (shown in Fig. 4).

In a differential optical absorption spectroscopy retrieval (Platt and Stutz, 2008), the column density $S$ of one or multiple absorbers $i$ (in this initial case, just $\mathrm{SO}_{2}$ ) in the instrument's light path is derived by fitting the laboratory absorption cross sections $\sigma_{i}$ to the measured optical density, along with a polynomial $P_{\lambda}$ (we use a fifth order) to account for broadband spectral features. We varied this approach slightly, and instead fit the $\mathrm{SO}_{2}$ absorption cross section $\sigma_{\mathrm{SO}_{2}}$ and the

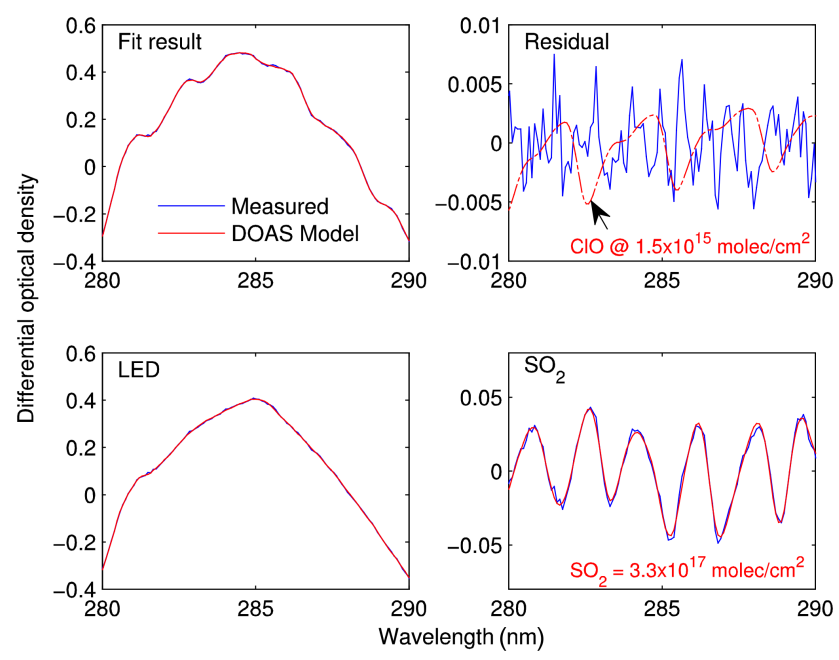

Figure 4. Evaluation of $\mathrm{SO}_{2}$ absorption in the measured spectra. The absorption cross section of $\mathrm{SO}_{2}$ was fitted to the differential optical depth. In this example evaluation, a column density of $1.5 \times 10^{17}$ molec $\mathrm{cm}^{-2}$ was retrieved. The detection limit of $\mathrm{ClO}$ was derived by comparing the fit residual with the absorption features of a hypothetical column density of $1.5 \times 10^{15} \mathrm{ClO}$ molec $\mathrm{cm}^{-2}$. See text for details.

logarithm of the shortcut spectrum $I_{0}$ to the logarithm of the measurement spectrum $I$, as shown in Eq. (3).

$\ln I=\ln I_{0}-\sum_{i} \sigma_{i} S_{i}+P_{\lambda}$

In this manner, a slight shift in wavelength calibration of the spectrometer between shortcut and measurement, should this occur, can be accounted for in the fit. Since the spectral resolution of the instrument does not match that of the laboratory reference (we use the $\mathrm{SO}_{2}$ cross section measured by Vandaele et al., 2009), the reference cross section is convolved with the instrument line shape before the fit is performed. The line shape or so-called "slit function" was characterised by recording the spectrum of a mercury vapour lamp and measuring the shape of a single atomic emission line at the spectrometer's resolution. The convolved cross section was then used in the fit.

An example of the $\mathrm{SO}_{2}$ fit is shown in Fig. 4. In this example, an $\mathrm{SO}_{2}$ column density of $1.5 \times 10^{17} \mathrm{molec} \mathrm{cm}^{-2}$ of $\mathrm{SO}_{2}$ was retrieved. The residual, shown at the top right of the figure and representing the difference between the measured spectrum and the fit result, is about $1 \%$ peak to peak. When compared to the $\mathrm{SO}_{2}$ absorption cross section, this noise level corresponds to an $\mathrm{SO}_{2}$ detection limit of approximately $2 \times 10^{16} \mathrm{molec} \mathrm{cm}^{-2}$ or 8 parts per million $\times$ metres (ppmm). In other words, concentrations below $1 \mathrm{ppm}$ can be detected along a $10 \mathrm{~m}$ total path ( $5 \mathrm{~m}$ one way). 
The results of the $\mathrm{SO}_{2}$ evaluation for the spectra recorded during the first measurement period at the lowtemperature fumarole are shown in Fig. 5a. The time series is characterised by a strong fluctuation of $\mathrm{SO}_{2}$ column densities in time which is mainly caused by wind blowing the fumarolic gas into or out of the light path of the instrument. At times, the retrieved $\mathrm{SO}_{2}$ column density reached up to $2.8 \times 10^{17} \mathrm{molec} \mathrm{cm}^{-2}(\sim 110 \mathrm{ppmm})$. Assuming a total optical path length of up to $30 \mathrm{~m}$ in the fumarolic gas (see Fig. 3a), this would correspond to an average $\mathrm{SO}_{2}$ mixing ratio of $3.7 \mathrm{ppm}$.

The second optical path that was chosen was more favourable in that it did not pass through as dense a gas plume as in the first measurement period (Fig. 3b). This led to a lower opacity and slower fluctuations in $\mathrm{SO}_{2}$ column density (Fig. 5b). Up to $1.2 \times 10^{18}$ molec cm $^{-2}$ ( $\sim 480$ ppmm) of $\mathrm{SO}_{2}$ were measured along this $200 \mathrm{~m}$ (one-way) path. We estimate that the volcanic gas filled about $1 / 4$ of the optical path for this measurement. Under this assumption, the measured column density corresponds to an average mixing ratio of about $4.8 \mathrm{ppm}$. When further taking into account that this plume was considerably more diluted than the plume measured at the first position, this second plume appears to have a significantly higher $\mathrm{SO}_{2}$ fraction. This finding is in agreement with the results of Aiuppa et al. (2005), who also found a significantly higher $\mathrm{SO}_{2}$ fraction in the plume originating from the inner-crater fumaroles. The combination of slower column density fluctuations and improved integration time (typically shorter than $300 \mathrm{~ms}$ ) also led to smaller errors in the retrieval for this time period (see next section).

\subsection{Rapid variation of gas and aerosol concentrations in the optical path}

The errors in the results obtained for the first measurement site (depicted in Fig. 5a) are significant, particularly for individual measurements of high column densities preceded and followed by lower values. The relatively large error in these measurements therefore appears to be associated with a change in gas and/or aerosol concentration in the instrument's light path during a measurement. Here we discuss the instrument's sensitivity to such fluctuations.

Two effects can be separated. First, the concentration of aerosols and water droplets in the light path can change over time. A portion of the light emitted by the LP-DOAS instrument is scattered onto particles and droplets while passing along the open optical path. In the narrow beam approximation (Platt and Stutz, 2008), light that has been scattered once will not re-enter the light path, and is therefore removed from the system. This leads to a reduction in the light intensity received by the telescope and inherently decreases the SNR of the measurement according to photon statistics.

However, the DOAS approach is not susceptible to a systematic error when the intensity changes during an exposure. Since a polynomial $P_{\lambda}$ is included in the fit to account for (a)

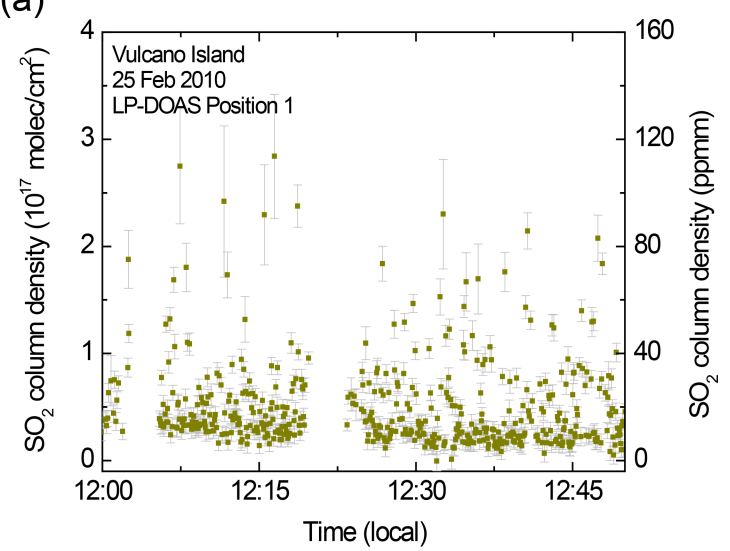

(b)

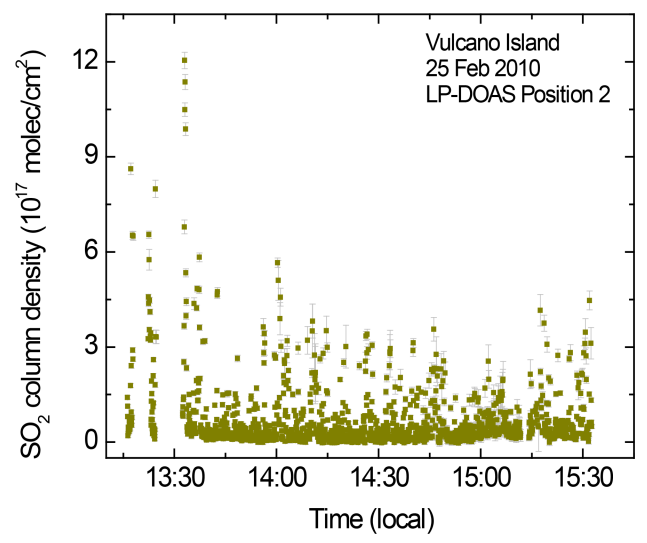

Figure 5. Time series of $\mathrm{SO}_{2}$ column densities measured in the two experiments at the island of Vulcano on 25 February 2010. (a) depicts the results obtained during the first measurement period at a low-temperature fumarole on the crater rim, and (b) depicts the results obtained while measuring gas stemming from the fumaroles along the base of the crater during the second measurement period. Rapid fluctuations in column density arise from various amounts of gas being blown into the optical path of the LPDOAS system.

broadband spectral features such as those associated with particle scattering (see Eq. 3), the column density $S$ is retrieved solely from the differential depth of the narrowband absorption lines of the respective trace gas. If the broadband intensity of radiation returning from the atmospheric path changes without a change in the relative depth of the absorption lines, an exposure integrated over this change will still exhibit the differential optical depth associated with the encountered gas column density. This can easily be shown for two spectra with different on-band intensities $I_{1}$ and $I_{2}$, and off-band intensities $I_{0,1}$ and $I_{0,2}$. If we require that

$\frac{I_{1}}{I_{0,1}}=\frac{I_{2}}{I_{0,2}}$ 


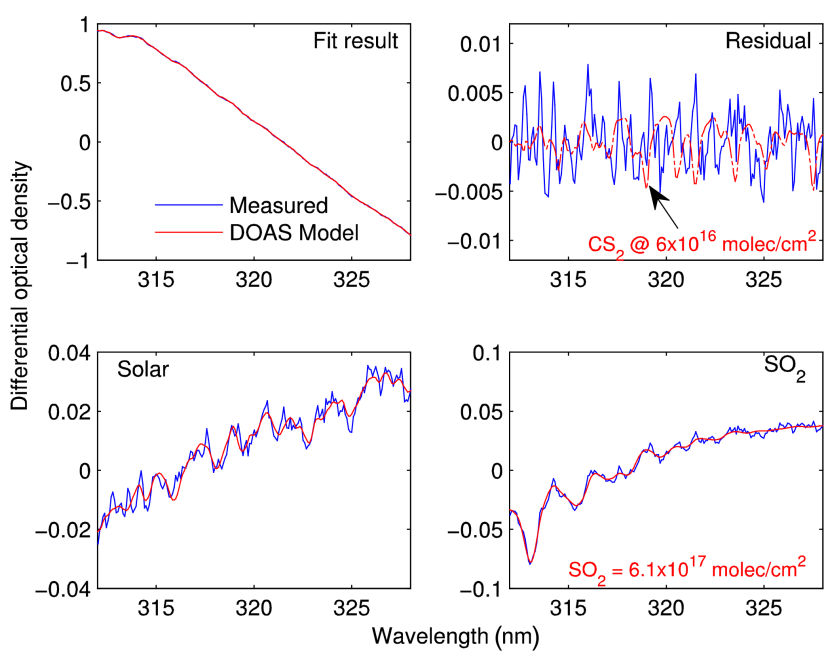

Figure 6. Evaluation of the measured spectra for $\mathrm{CS}_{2}$ absorption. Here, a solar spectrum was included in the fit to remove features associated with scattered solar radiation entering the instrument's light path (Ring spectrum not shown for clarity). $\mathrm{CS}_{2}$ was not detected during the experiments, but an upper limit could be determined from the fit residual. Here, the residual is compared to the absorption features associated with a hypothetical column density of $6 \times 10^{16} \mathrm{CS}_{2}$ molec $\mathrm{cm}^{-2}$.

in other words, that the amount of gas in the light path be constant (see Eq. 2), then

$$
\begin{aligned}
& \frac{I}{I_{0}}=\frac{I_{1}+I_{2}}{I_{0,1}+I_{0,2}}=\frac{\left(I_{1}+I_{2}\right) I_{0,2}}{\left(I_{0,1}+I_{0,2}\right) I_{0,2}}=\frac{I_{1} \cdot I_{0,2}+I_{2} \cdot I_{0,2}}{I_{0,1} \cdot I_{0,2}+I_{0,2}^{2}} \\
& \stackrel{\text { Eq. (4) }}{\stackrel{I_{2} \cdot I_{0,1}+I_{2} \cdot I_{0,2}}{I_{0,1} \cdot I_{0,2}+I_{0,2}^{2}}}=\frac{I_{2}\left(I_{0,1}+I_{0,2}\right)}{I_{0,2}\left(I_{0,1}+I_{0,2}\right)}=\frac{I_{2}}{I_{0,2}}=\frac{I_{1}}{I_{0,1}} .
\end{aligned}
$$

Therefore, the optical depth $\tau$ will remain an accurate measure of the column density $S$ of gas in the instrument's well-defined light path (Eq. 2) if only the aerosol concentration changes. This stands in contrast to the effect that aerosols have on passive DOAS measurements which use scattered solar radiation to measure volcanic gases. For these, any change in the aerosol concentration along the viewing direction will directly influence the atmospheric light path along which the measurement is being conducted, thus also potentially changing the measured optical depth $\tau$ and greatly impacting the accuracy of the measurement (Kern et al., 2009).

Particles and water droplets in the LP-DOAS optical path can also scatter solar radiation into the receiving optics of the instrument. This leads to a "background" solar spectrum that appears superimposed on the spectrum of the active light sources (shown in Fig. 2a). This contribution to the measurement needs to be corrected during the spectral retrieval, as is discussed in the next section. Correction is not necessary when operating at wavelengths shorter than
$300 \mathrm{~nm}$ (as we do here), because solar radiation is negligible in this region.

The second effect that can occur during a measurement is a rapid change in the column density $S$ of the measured trace gas. This effect is significantly more problematic than a change in the aerosol concentration. When measuring volcanic plumes, the two effects will often occur simultaneously as $\mathrm{SO}_{2}$ and aerosol-rich volcanic gas is blown into and out of the instrument light path. If we assume a constant off-band intensity $I_{0}$, then a change in trace gas column density will lead to a change in the on-band intensity of a measurement from $I_{1}$ to $I_{2}$. If these two successive measurements are coadded (or integrated during a single exposure of the CCD), the optical depth $\tau$ can be calculated from the sum of the individual intensities:

$$
\begin{aligned}
\tau & =\ln \frac{I_{1}+I_{2}}{2 I_{0}}=\ln \frac{I_{1}\left(1+\frac{I_{2}}{I_{1}}\right)}{2 I_{0}}=\ln \frac{I_{1}}{I_{0}}+\ln \frac{1+\frac{I_{2}}{I_{1}}}{2} \\
& =\tau_{1}+\ln \frac{1+\frac{I_{2}}{I_{1}}}{2} \neq \frac{1}{2}\left(\tau_{1}+\tau_{2}\right)
\end{aligned}
$$

Equation 6 shows that, owing to the nonlinearity of the Beer-Lambert-Bouguer law (Eq. 2), $\tau$ is not equal to the average of the two optical depths $\tau_{1}$ and $\tau_{2}$ associated with the gas column densities at time 1 and time 2 . Instead, there is a systematic shift towards lower optical depths. This effect will also influence the shape of the absorption lines in the measured spectra, and the fit of the absorption cross sections according to Eq. (3) will result in a systematic residual structure. Accurate measurements therefore require that the exposure time be short compared to the timescales over which the column density of the absorbers changes in the light path.

During our test measurements at the first site, individual spectra were recorded at exposure times varying between approximately 150 and $600 \mathrm{~ms}$, depending on the opacity of the plume in the light path at any given time. Because the retroreflector was positioned in direct proximity to the fumaroles, high opacities were encountered fairly often, and exposure times of $\sim 600 \mathrm{~ms}$ were not uncommon. As shown above, changes in plume opacity alone will not lead to systematic errors, but in this case, such changes were likely accompanied by changes in the gas column in the instrument's light path, as the fumarole's plume drifted in and out. This often led to a misfit between measured optical depth and the absorption cross section and, thus, resulted in the relatively large errors (Fig. 5a). During the measurements conducted at the second site, generally lower plume opacities led to shorter exposure times. Thus, the assumption of a constant $\mathrm{SO}_{2}$ column density in the light path is valid, and the errors are significantly reduced (Fig. 5b). To avoid systematic errors in the future, care must be taken to ensure that the exposure time is always shorter than the timescale of variations in the trace gas column density, even if this leads to undersaturated exposures and, associated with this, slightly decreased SNRs for the measurement. 


\section{3 $\mathrm{ClO}$ and $\mathrm{CS}_{2}$ detection limits}

Besides $\mathrm{SO}_{2}, \mathrm{CS}_{2}$ and $\mathrm{ClO}$ both have characteristic absorption features in the $260-360 \mathrm{~nm}$ wavelength region (Fig. 2). The absorption cross section of $\mathrm{ClO}$ was originally included in the $\mathrm{SO}_{2}$ fit described above, but no differential features associated with $\mathrm{ClO}$ absorption were detected during the evaluation, so it was later omitted from the $\mathrm{SO}_{2}$ retrieval. In an attempt to improve the SNR of the measurement and thereby improve the $\mathrm{ClO}$ detection limit, the evaluated spectra were sorted by their $\mathrm{SO}_{2}$ column density, binned in groups of 10 to 20 such that all spectra in a single group had comparable $\mathrm{SO}_{2}$ columns, and co-added to improve the statistics of the measurement.

These spectra were again evaluated for $\mathrm{ClO}$ absorption, but none was found. Due to their high solubility in water, halogen gases are very efficiently scrubbed when passing through large-scale hydrothermal systems (Symonds et al., 2001). Considering the significant hydrothermal activity at the island of Vulcano, it is therefore not surprising that halogen emissions appear negligible. However, an upper limit could be derived from the spectral retrieval. For this, the magnitude of the fit residual was analysed.

The fit residual represents the difference between the measured optical depth and the optical depth derived from the DOAS fit. Absorption structures of gases not accounted for by the fit would appear in the residual. For a given measurement spectrum, the detection limit of a gas species not included in the DOAS model can therefore be derived by comparing the fit residual with the absorption cross section of that species multiplied by a hypothetical column density. This is demonstrated in Fig. 4. Here, the magnitude of the fit residual is compared to the absorption features associated with a hypothetical column density of $1.5 \times 10^{15} \mathrm{ClO}$ molec cm ${ }^{-2}$. By making the conservative assumption that any $\mathrm{ClO}$ absorption features larger than these could not be masked by the noise in the fit residual, a column of $1.5 \times 10^{15} \mathrm{ClO}$ molec $\mathrm{cm}^{-2}$ represents the upper limit for this particular spectrum. This corresponds to a path-averaged mixing ratio of about $1.5 \mathrm{ppb}$ (note that the volcanic gas only fills part of the $400 \mathrm{~m}$ total light path) and an upper limit for the $\mathrm{ClO} / \mathrm{SO}_{2}$ ratio of about $5 \times 10^{-3}$ for this example. When analysing the entire collected data set, and particularly the co-added spectra containing larger amounts of $\mathrm{SO}_{2}$ than in the given example, an upper limit for the $\mathrm{ClO} / \mathrm{SO}_{2}$ molar ratio of about $2 \times 10^{-3}$ was obtained for the emissions from the fumaroles on the edge of the crater floor. Considering an average $\mathrm{SO}_{2}$ emission rate from the fumarolic area of about $12 \mathrm{td}^{-1}$ (as reported by Vita et al. (2012) for the 2008-2010 period), this corresponds to an approximate upper limit for the $\mathrm{ClO}$ flux of $20 \mathrm{~kg} \mathrm{~d}^{-1}$.

Finally, the recorded spectra were also evaluated with regards to the potential absorption of $\mathrm{CS}_{2}$. $\mathrm{CS}_{2}$ was first measured by DOAS in the urban atmosphere above Shanghai by
Yu et al. (2004). Though it has never been detected by DOAS in a volcanic environment, an attempt was made here, because reduced sulfur species (particularly $\mathrm{H}_{2} \mathrm{~S}$, Aiuppa et al., 2006) are known to be present in abundance in the fumaroles at La Fossa crater on the island of Vulcano, where these measurements were made. The differential absorption features of $\mathrm{CS}_{2}$ in the 310-330 nm wavelength range (Fig. 2) do make it potentially accessible to our LP-DOAS instrument. A separate $\mathrm{CS}_{2}$ evaluation was performed in which the wavelength region between 312 and $328 \mathrm{~nm}$ was analysed. At shorter wavelengths, strong $\mathrm{SO}_{2}$ absorption interfered with the measurement. At longer wavelengths, the intensity of the available LED was insufficient. In addition to the cross section of $\mathrm{CS}_{2}$, the cross section of $\mathrm{SO}_{2}$ was included in the fit, as well as a reference spectrum compiled from 60 spectra without $\mathrm{SO}_{2}$ absorption. A fifth-order polynomial was again used to account for any broadband structures in the retrieval. Because this retrieval was performed at wavelengths longer than $300 \mathrm{~nm}$, the spectrum of solar radiation scattered into the instrument's light path by condensed water droplets and volcanogenic aerosols was found superimposed onto the LED spectra. This is clearly demonstrated by the non-zero baseline at $350 \mathrm{~nm}$ in the example spectrum shown in Fig. $2 \mathrm{~b}$. To correct for this effect, a Fraunhofer solar reference spectrum (measured with the same geometry but with the LED switched off) and a Ring spectrum (used to correct for inelastic scattering in the atmosphere, Grainger and Ring, 1962) were also included in the fit.

As was the case for $\mathrm{ClO}, \mathrm{CS}_{2}$ concentrations were below the instrument's detection limit throughout the measurement period. However, the same approach was used to derive an upper limit for the $\mathrm{CS}_{2} / \mathrm{SO}_{2}$ molecular ratio in the fumarolic emissions. $\mathrm{CS}_{2}$ was omitted from the DOAS model and, after the fit accounted for $\mathrm{SO}_{2}$ absorption and interference from solar radiation scattered into the optical path, the fit residual was compared to the absorption features of hypothetical columns of $\mathrm{CS}_{2}$. Figure 6 shows an example in which an upper limit of $6 \times 10^{16} \mathrm{CS}_{2}$ molec $\mathrm{cm}^{-2}(\sim 24 \mathrm{ppmm})$ was obtained. This corresponds to an upper limit for the pathintegrated average mixing ratio of about $60 \mathrm{ppb}, \mathrm{a} \mathrm{CS}_{2} / \mathrm{SO}_{2}$ molecular ratio of less than 0.1 and an average $\mathrm{CS}_{2}$ flux of less than about $1.4 \mathrm{td}^{-1}$ (again assuming an average $\mathrm{SO}_{2}$ emission rate of $12 \mathrm{t} \mathrm{d}^{-1}$ as reported by Vita et al., 2012).

\section{Conclusions and outlook}

Recent technological advances in fibre-coupled telescopes and UV-LED technology have made design and construction of a mobile active LP-DOAS for use in remote environments possible. Here, we built an instrument specifically for measuring volcanic gas emissions. The tests conducted at La Fossa crater, Vulcano, showed that in the current configuration, the instrument is highly sensitive to $\mathrm{SO}_{2}$, with openpath measurements of $\mathrm{SO}_{2}$ column densities as low as about 
$2 \times 10^{16} \mathrm{molec} \mathrm{cm}^{-2}(\sim 8 \mathrm{ppmm})$ possible. For the $400 \mathrm{~m}$ total light path length used here, this corresponds to a detection limit of about $20 \mathrm{ppb} \mathrm{SO}_{2}$ averaged along the light path, but even higher sensitivities could potentially be achieved by using longer light paths.

Collocation of the LP-DOAS with laser absorption-based open-path $\mathrm{CO}_{2}$ instruments would enable the quantification of $\mathrm{CO}_{2} / \mathrm{SO}_{2}$ ratios in the bulk plume, not just at a single location within the plume, as stationary in situ techniques currently allow. In fact, both instruments can use the same retroreflector as long as a fused-silica prism assembly is chosen. At the same time, the low power consumption and lack of moving parts make the instrument significantly more portable and durable than FTIR spectrometers, which previously represented the only remote sensing approach to obtaining this geochemical parameter. Despite the difficulties involved with making measurements in the past, monitoring the $\mathrm{CO}_{2} / \mathrm{SO}_{2}$ ratio at active volcanoes throughout the world has already led to significant insights into volcanic processes (Duffell et al., 2003; Allard et al., 2005; Aiuppa et al., 2007; Burton et al., 2007; Shinohara et al., 2008, 2011; Ohba et al., 2011; Werner et al., 2012, 2013) and allows the estimation of $\mathrm{CO}_{2}$ input into the atmosphere from global volcanism (Burton et al., 2013). In the future, mobile LP-DOAS instruments could help quantify this parameter at hitherto inaccessible volcanic systems. The fact that the LP-DOAS instruments need not be located within the volcanic plume itself also makes them potentially attractive for long-term continuous monitoring, as the highly corrosive gases in volcanic plumes make permanent installation of equipment in their midst extremely difficult. The retroreflectors are made of plastic and fused silica and can be located in corrosive plumes without fear of damaging them (although periodic cleaning is necessary). This allows the light path length to be adapted to the expected plume opacity, with short light paths chosen for very dense plumes. The technical difficulties and safety concerns associated with approaching an active volcanic vent probably represent the main limitations to instrument applicability at a given location.

Aside from $\mathrm{SO}_{2}$ measurements, there is also significant potential for the quantitative detection of other volatile species in volcanic plumes using the described LP-DOAS instrumentation. Though neither $\mathrm{ClO}$ nor $\mathrm{CS}_{2}$ column densities were found above the instrument's detection limits in the fumarolic gases at La Fossa crater, the instrument sensitivity would be sufficient to detect $\mathrm{ClO}$ in volcanic environments in which it is present in higher abundances. For example, Lee et al. (2005) report a $\mathrm{ClO} / \mathrm{SO}_{2}$ ratio of $5 \times 10^{-2}$ in the plume of Sakurajima volcano (Japan), a value that is more than 1 order of magnitude above the detection limit of our LP-DOAS. On the other hand, little is known about the actual magnitude of $\mathrm{CS}_{2}$ emissions from volcanic systems, so it is unclear whether the achieved detection limit will make the LP-DOAS a valuable tool for assessing this trace species. Globally, $\mathrm{CS}_{2}$ is only a very minor component (Halmer et al., 2002) when compared to other sulfur-bearing species (mainly $\mathrm{SO}_{2}$ and $\mathrm{H}_{2} \mathrm{~S}$ ), but trace amounts have been reported both in explosive eruption plumes (Rasmussen et al., 1982) and in fumarolic gases (Stoiber et al., 1971), so its exact role remains uncertain, and abundances may vary widely from system to system.

The described LP-DOAS system can also be used to measure other volcanic volatiles (Fig. 2), most notably perhaps the halogen oxide compounds $\mathrm{OClO}$ and $\mathrm{BrO}$. The design of the fibre-coupling system allows the addition of LEDs at other wavelengths if targeting species with absorption cross sections outside the current range. Alternatively, three LEDs emitting at the same wavelength can be used to improve the light throughput and SNR of the system at that wavelength. Another envisioned modification that will likely further improve the sensitivity of the instrument is the implementation of a pulsed LED power supply. The optical output power of LEDs is limited by the heat generated by the dissipated electrical input power. Therefore, LEDs can be pulsed at significantly higher input currents than they can sustain in continuous operation. Such a pulsed operation does not significantly improve the time-integrated optical output power of the LEDs but, if synchronised with the spectrometer readout electronics, the system could measure the background spectrum during periods when the LEDs are off, thus providing a more or less contemporaneous measurement of the background solar radiation scattered into the light path. Currently, accurate correction of the scattered solar contribution appears to be one of the main limitations of the system, particularly when applying it to opaque, optically thick plumes, and a pulsed acquisition stands to improve this correction significantly.

The flexibility of the system allows application to a wide range of volcanic system types, from active high-temperature vents to hydrothermal fumarole fields. The active light sources allow measurements to be made both during the day and at night, which can provide insights into the photochemistry taking place in volcanic plumes, as for example shown by Kern et al. (2008). The instrument's light weight, rugged design and low power consumption allow active DOAS measurements to be made at remote locations that were previously inaccessible. It therefore has the potential to make significant improvements to our ability to monitor and understand geochemical processes in volcanic systems around the world.

Acknowledgements. The authors would like to acknowledge Tom Pering, Tamar Elias and two anonymous reviewers for their thoughtful reviews of the manuscript. Any use of trade, firm, or product names is for descriptive purposes only and does not imply endorsement by the US Government.

Edited by: A. Schütze

Reviewed by: three anonymous referees 


\section{References}

Aiuppa, A., Federicao, C., Giudice, G., and Gurrieri, S.: Chemical mapping of a fumarolic field: La Fossa Crater, Vulcano Island (Aeolian Islands, Italy), Geophys. Res. Lett., 32, L13309, doi:10.1029/2005GL023207, 2005.

Aiuppa, A., Federico, C., Giudice, G., Gurrieri, S., and Valenza, M.: Hydrothermal buffering of the $\mathrm{SO}_{2} / \mathrm{H}_{2} \mathrm{~S}$ ratio in volcanic gases: Evidence from La Fossa Crater fumarolic field, Vulcano Island, Geophys. Res. Lett., 33, L21315, doi:10.1029/2006GL027730, 2006.

Aiuppa, A., Moretti, R., Federico, C., Giudice, G., Gurrieri, S., Liuzzo, M., Papale, P., Shinohara, H., and Valenza, M.: Forecasting Etna eruptions by real-time observation of volcanic gas composition, Geology, 35, 1115, doi:10.1130/G24149A.1, 2007.

Allard, P., Burton, M., and Muré, F.: Spectroscopic evidence for a lava fountain driven by previously accumulated magmatic gas, Nature, 433, 407-410, doi:10.1038/nature03246, 2005.

Bogumil, K., Orphal, J., Homann, T., Voigt, S., Spietz, P., Fleischmann, O. C., Vogel, A., Hartmann, M., Bovensmann, H., Frerick, J., and Burrows, J. P.: Measurementsof molecular absorption spectra with the SCIAMACHY pre-flight model: Instrument characterization and reference data for atmospheric remote sensing in the $230-2380 \mathrm{~nm}$ region, J. Photoch. Photobio. A, 157, 167-184, 2003.

Burton, M. R., Oppenheimer, C. M., Horrocks, L. A., and Francis, P. W.: Remote sensing of $\mathrm{CO}_{2}$ and $\mathrm{H}_{2} \mathrm{O}$ emission rates from Masaya volcano, Nicaragua, Geology, 28, 915-918, 2000.

Burton, M. R., Sawyer, G. M., and Granieri, D.: Deep Carbon Emissions from Volcanoes, Rev. Mineral. Geochem., 75, 323-354, doi:10.2138/rmg.2013.75.11, 2013.

Burton, M., Allard, P., Muré, F., and La Spina, A.: Magmatic gas composition reveals the source depth of slugdriven strombolian explosive activity., Science, 80, 227-230, doi:10.1126/science.1141900, 2007.

Carapezza, M. L., Barberi, F., Ranaldi, M., Ricci, T., Tarchini, L., Barrancos, J., Fischer, C., Perez, N., Weber, K., Di Piazza, A., and Gattuso, A.: Diffuse $\mathrm{CO}_{2}$ soil degassing and $\mathrm{CO}_{2}$ and $\mathrm{H}_{2} \mathrm{~S}$ concentrations in air and related hazards at Vulcano Island (Aeolian arc, Italy), J. Volcanol. Geoth. Res., 207, 130-144, doi:10.1016/j.jvolgeores.2011.06.010, 2011.

Carn, S. A., Krotkov, N. A., Yang, K., and Krueger, A. J.: Measuring global volcanic degassing with the Ozone Monitoring Instrument (OMI), in: Remote Sensing of Volcanoes and Volcanic Processes: Integrating Observations and Modelling, edited by: Pyle, D. M., Mather, T. A., and Biggs, J., Geological Society, London, 2013.

Chan, K. L., Pöhler, D., Kuhlmann, G., Hartl, A., Platt, U., and Wenig, M. O.: $\mathrm{NO}_{2}$ measurements in Hong Kong using LED based long path differential optical absorption spectroscopy, Atmos. Meas. Tech., 5, 901-912, doi:10.5194/amt-5-901-2012, 2012.

Duffell, H. J., Oppenheimer, C., Pyle, D. M., Galle, B., McGonigle, A. J., and Burton, M. R.: Changes in gas composition prior to a minor explosive eruption at Masaya volcano, Nicaragua, J. Volcanol. Geoth. Res., 126, 327-339, doi:10.1016/S03770273(03)00156-2, 2003.

Galle, B., Johansson, M., Rivera, C., Zhang, Y., Kihlman, M., Kern, C., Lehmann, T., Platt, U., Arellano, S., and Hidalgo, S.: Network for Observation of Volcanic and Atmospheric Change (NOVAC)
- A global network for volcanic gas monitoring: Network layout and instrument description, J. Geophys. Res., 115, D05304, doi:10.1029/2009JD011823, 2010.

Gerlach, T. M., Delgado, H., Mcgee, K. A., Doukas, M. P., Venegas, J. J., and Cardenas, L.: Application of the LI-COR $\mathrm{CO}_{2}$ analyzer to volcanic plumes: A case study, volcan Popocatepetl, Mexico, 7 and 10 June, 1995, J. Geophys. Res., 102, 8005-8019, 1997.

Gerlach, T. M., Mcgee, K. A., Sutton, A. J., and Elias, T.: Rates of volcanic $\mathrm{CO}_{2}$ degassing from airborne determinations of $\mathrm{SO}_{2}$ emission rates and plume $\mathrm{CO}_{2} / \mathrm{SO}_{2}$ : Test study at $\mathrm{Pu}$ ' $\mathrm{u}$ ' $\mathrm{O}$ 'o Cone, Kilauea volcano, Hawaii, Geophys. Res. Lett., 25, 26752678, 1998.

Giggenbach, W. F. and Goguel, R. L.: Methods for collection and analysis of geothermal and volcanic water and gas samples, Dep. Sci. Ind. Res. Chem. Div., Report 240, 1989.

Grainger, J. F. and Ring, J.: Anomalous Fraunhofer Line Profiles, Nature, 193, 762 pp., 1962.

Halmer, M. M., Schmincke, H.-U., and Graf, H.-F., The annual volcanic gas input into the atmosphere, in particular into the stratosphere: a global data set for the past 100 years, J. Volcanol. Geoth. Res., 115, 511-528, doi:10.1016/S0377-0273(01)003183, 2002.

Kern, C., Trick, S., Rippel, B., and Platt, U.: Applicability of lightemitting diodes as light sources for active differential optical absorption spectroscopy measurements, Appl. Optics, 45, 20772088, 2006.

Kern, C., Sihler, H., Vogel, L., Rivera, C., Herrera, M., and Platt, U.: Halogen oxide measurements at Masaya Volcano, Nicaragua using active long path differential optical absorption spectroscopy, B. Volcanol., 71, 659-670, doi:10.1007/s00445008-0252-8, 2008.

Kern, C., Deutschmann, T., Vogel, L., Wöhrbach, M., Wagner, T., and Platt, U.: Radiative transfer corrections for accurate spectroscopic measurements of volcanic gas emissions, B. Volcanol., 72, 233-247, doi:10.1007/s00445-009-0313-7, 2009.

Lee, C., Kim, Y. J., Tanimoto, H., Bobrowski, N., Platt, U., Mori, T., Yamamoto, K., and Hong, C. S.: High $\mathrm{ClO}$ and ozone depletion observed in the plume of Sakurajima volcano, Japan, Geophys. Res. Lett., 32, 10-13, doi:10.1029/2005GL023785, 2005.

Merten, A., Tschritter, J., and Platt, U.: Design of differential optical absorption spectroscopy long-path telescopes based on fiber optics, Appl. Optics, 50, 738-54, 2011.

O'Dwyer, M.: Real-time measurement of volcanic $\mathrm{H}_{2} \mathrm{~S}$ and $\mathrm{SO}_{2}$ concentrations by UV spectroscopy, Geophys. Res. Lett., 30, 1215, doi:10.1029/2003GL017246, 2003.

Ohba, T., Daita, Y., Sawa, T., Taira, N., and Kakuage, Y.: Coseismic changes in the chemical composition of volcanic gases from the Owakudani geothermal area on Hakone volcano, Japan, B. Volcanol., 73, 457-469, doi:10.1007/s00445-010-0445-9, 2011.

Oppenheimer, C., Francis, P., Burton, M., Maciejewski, A. J. H., and Boardman, L.: Remote measurement of volcanic gases by Fourier transform infrared spectroscopy, Appl. Phys. B, 67, 505$515,1998$.

Oppenheimer, C., Scaillet, B., and Martin, R. S.: Sulfur Degassing From Volcanoes: Source Conditions, Surveillance, Plume Chemistry and Earth System Impacts, Rev. Mineral. Geochem., 73, 363-421, doi:10.2138/rmg.2011.73.13, 2011.

Pedone, M., Aiuppa, A., Giudice, G., Grassa, F., Cardellini, C., Chiodini, G., and Valenza, M.: Volcanic $\mathrm{CO}_{2}$ flux measurement 
at Campi Flegrei by tunable diode laser absorption spectroscopy, B. Volcanol., 76, 812, doi:10.1007/s00445-014-0812-z, 2014.

Pering, T. D., Tamburello, G., McGonigle, A. J. S., Aiuppa, A., Cannata, A., Giudice, G., and Patanè, D.: High time resolution fluctuations in volcanic carbon dioxide degassing from Mount Etna, J. Volcanol. Geoth. Res., 270, 115-121, doi:10.1016/j.jvolgeores.2013.11.014, 2014.

Platt, U. and Stutz, J.: Differential Optical Absorption Spectroscopy, Springer, Berlin, Heidelberg, 2008.

Platt, U., Perner, D., and Patz, H. W.: Simultaneous Measurement of Atmospheric $\mathrm{CH}_{2} \mathrm{O}, \mathrm{O}_{3}$, and $\mathrm{NO}_{2}$ by Differential Optical Absorption, J. Geophys. Res., 84, 6329-6335, 1979.

Rasmussen, R. A., Khalil, M. A., Dalluge, R. W., Penkett, S. A., and Jones, B.: Carbonyl sulfide and carbon disulfide from the eruptions of mount st. Helens., Science, 215, 665-667, doi:10.1126/science.215.4533.665, 1982.

Rawlins, W. T., Hensley, J. M., Sonnenfroh, D. M., Oakes, D. B., and Allen, M. G.: Quantum cascade laser sensor for $\mathrm{SO}_{2}$ and $\mathrm{SO}_{3}$ for application to combustor exhaust streams, Appl. Optics, 44, 6635-6643, 2005.

Richter, D., Erdelyi, M., Curl, R. F., Tittel, F. K., Oppenheimer, C., Duffell, H. J., and Burton, M.: Field measurements of volcanic gases using tunable diode laser based mid-infrared and Fourier transform infrared spectrometers, Opt. Laser Eng., 37, 171-186, doi:10.1016/S0143-8166(01)00094-X, 2002.

Roberts, T. J., Braban, C. F., Oppenheimer, C., Martin, R. S., Freshwater, R. A., Dawson, D. H., Griffiths, P. T., Cox, R. A., Saffell, J. R., and Jones, R. L.: Electrochemical sensing of volcanic gases, Chem. Geol., 332-333, 74-91, doi:10.1016/j.chemgeo.2012.08.027, 2012.

Roberts, T. J., Saffell, J. R., Oppenheimer, C., and Lurton, T.: Electrochemical sensors applied to pollution monitoring: Measurement error and gas ratio bias - A volcano plume case study, J. Volcanol. Geoth. Res., 281, 85-96, doi:10.1016/j.jvolgeores.2014.02.023, 2014.

Schiff, H. I., Mackay, G. I., and Bechara, J.: The use of tunable diode laser absorption spectroscopy for atmospheric measurements, in: Air Monitoring by Spectroscopic Techniques, edited: by M. W. Sigrist, 239-333, John Wiley and Sons, Inc., New York, Chister, Brisbane, Toronto, Singapore, 1994.

Sensor Electronic Technology, I., UVTOP Deep UV LED Technical Catalogue, 1-40, 2014.

Shinohara, H.: A new technique to estimate volcanic gas composition: plume measurements with a portable multisensor system, J. Volcanol. Geoth. Res., 143, 319-333, doi:10.1016/j.jvolgeores.2004.12.004, 2005.

Shinohara, H., Aiuppa, A., Giudice, G., Gurrieri, S., and Liuzzo, M.: Variation of $\mathrm{H}_{2} \mathrm{O} / \mathrm{CO}_{2}$ and $\mathrm{CO}_{2} / \mathrm{SO}_{2}$ ratios of volcanic gases discharged by continuous degassing of Mount Etna volcano, Italy, J. Geophys. Res., 113, B09203, doi:10.1029/2007JB005185, 2008.
Shinohara, H., Matsushima, N., Kazahaya, K., and Ohwada, M.: Magma-hydrothermal system interaction inferred from volcanic gas measurements obtained during 2003-2008 at Meakandake volcano, Hokkaido, Japan, B. Volcanol., 73, 409-421, doi:10.1007/s00445-011-0463-2, 2011.

Sihler, H., Kern, C., Pöhler, D., and Platt, U.: Applying lightemitting diodes with narrowband emission features in differential spectroscopy., Opt. Lett., 34, 3716-3718, 2009.

Stoiber, R. E., Leggett, D. C., Jenkins, T. F., Murrmann, R. P., and Rose, W. I.: Organic Compounds in Volcanic Gas from Santiaguito Volcano, Guatemala, Geol. Soc. Am. Bull., 82, 2299-2302, 1971.

Stremme, W., Krueger, A., Harig, R., and Grutter, M.: Volcanic $\mathrm{SO}_{2}$ and $\mathrm{SiF} 4$ visualization using 2-D thermal emission spectroscopy - Part 1: Slant-columns and their ratios, Atmos. Meas. Tech., 5, 275-288, doi:10.5194/amt-5-275-2012, 2012.

Symonds, R. B., Gerlach, T. M., and Reed, M. H.: Magmatic gas scrubbing: implications for volcano monitoring, J. Volcanol. Geoth. Res., 108, 303-341, doi:10.1016/S0377-0273(00)002924, 2001.

Tittel, F. K., Lewicki, R., Lascola, R., and McWhorter, S.: Emerging Infrared Laser Absorption Spectroscopic Techniques for Gas Analysis, in: Trace Analysis of Specialty and Electronic Gases, edited by: Geiger, W. M. and Raynor, M. W., 71-110, John Wiley and Sons, Inc., New York, Chister, Brisbane, Toronto, Singapore, 2012.

Vandaele, A. C., Hermans, C., and Fally, S.: Fourier transform measurements of $\mathrm{SO}_{2}$ absorption cross sections: II. Temperature dependence in the $29000-44000 \mathrm{~cm}^{-1}(345-420 \mathrm{~nm})$ region, J. Quant. Spectrosc. Ra., 110, 2115-2126, 2009.

Vita, F., Inguaggiato, S., Bobrowski, N., Calderone, L., Galle, B., and Parello, F.: Continuous $\mathrm{SO}_{2}$ flux measurements for Vulcano Island, Italy, Ann. Geophys., 55, 301-308, doi:10.4401/ag-5759, 2012.

Wahner, A., Ravishankara, A. R., Sander, S. P., and Friedl, R. R.: Absorption cross section of BrO between 312 and $385 \mathrm{~nm}$ at 298 and 223 K, Chem. Phys. Lett., 152, 507-512, 1988.

Werner, C., Evans, W. C., Kelly, P. J., McGimsey, R., Pfeffer, M., Doukas, M., and Neal, C.: Deep magmatic degassing versus scrubbing: Elevated $\mathrm{CO}_{2}$ emissions and $\mathrm{C} / \mathrm{S}$ in the lead-up to the 2009 eruption of Redoubt Volcano, Alaska, Geochem. Geophy. Geosyst., 13, Q03015, doi:10.1029/2011GC003794, 2012.

Werner, C., Kelly, P. J., Doukas, M., Lopez, T., Pfeffer, M., McGimsey, R., and Neal, C.: Degassing of $\mathrm{CO}_{2}, \mathrm{SO}_{2}$, and $\mathrm{H}_{2} \mathrm{~S}$ associated with the 2009 eruption of Redoubt Volcano, Alaska, J. Volcanol. Geotherm. Res., 259, 270-284, doi:10.1016/j.jvolgeores.2012.04.012, 2013.

Yu, Y., Geyer, A., Xie, P., Galle, B., Chen, L., and Platt, U.: Observations of carbon disulfide by differential optical absorption spectroscopy in Shanghai, Geophys. Res. Lett., 31, L11107, doi:10.1029/2004GL019543, 2004. 